\begin{tabular}{|c|c|c|c|}
\hline Article Info & \multicolumn{2}{|c|}{\begin{tabular}{l|l} 
RESEARCH ARTICLE & ARAŞTIRMA MAKALESİ \\
\end{tabular}} & \\
\hline Title of Article & \multicolumn{2}{|c|}{$\begin{array}{l}\text { Determination of Pedestrian-Friendly } \\
\text { Environments in Ordu City Center Using } \\
\text { the Pedestrian Environment Index (PEI) }\end{array}$} & \\
\hline $\begin{array}{l}\text { Corresponding } \\
\text { Author }\end{array}$ & \multicolumn{2}{|c|}{$\begin{array}{l}\text { Mesut GÜZEL } \\
\text { Ordu Üniversitesi, Ziraat Fakültesi, Peyzaj Mimarlığı Bölümü, mesutguzel@odu.edu.tr }\end{array}$} & \\
\hline $\begin{array}{l}\text { Received Date } \\
\text { Accepted Date }\end{array}$ & \multicolumn{2}{|l|}{$\begin{array}{l}15.05 .2021 \\
12.06 .2021\end{array}$} & \\
\hline DOI Number & \multicolumn{2}{|l|}{ https://doi.org/10.35674/kent.937170 } & \\
\hline Author / Authors & $\begin{array}{l}\text { Arş. Gör. Mesut GÜZEL } \\
\text { Doç. Dr. Murat YEŞiL }\end{array}$ & $\begin{array}{l}\text { ORCID: 0000-0001-6172-5812 } \\
\text { ORCID: 0000-0002-3643-5626 }\end{array}$ & \\
\hline How to Cite & \multicolumn{2}{|c|}{$\begin{array}{l}\text { Güzel, M. ve Yeşil, M. (2021). Ordu Kent Merkezindeki Yaya Dostu Bölgelerin } \\
\text { Yaya Çevre İndisi Kullanılarak Belirlenmesi, Kent Akademisi, Volume, 14, Issue 2, } \\
\text { Pages, 468-481 }\end{array}$} & $\begin{array}{l}\text { Kent Akademisi } \\
\text { Uriban Academy }\end{array}$ \\
\hline
\end{tabular}

\title{
Ordu Kent Merkezindeki Yaya Dostu Bölgelerin Yaya Çevre İndisi Kullanılarak Belirlenmesi
}

\begin{abstract}
:
Most of the cities are designed in such a way that long distances require the use of motor vehicles between the places where people live and the areas where they work, shop or spend their free time. However, the global epidemic, which has recently affected the whole world, has led to the questioning of transportation preferences and urban space fiction. The restriction of transportation and public mobility within the scope of the fight against the global epidemic has once again emphasized the importance of pedestrian-friendly cities. A pedestrian-friendly city; it is a living environment where its residents can meet their basic needs such as shopping, education, health and recreation in a short distance by walking or cycling. In various cities of the world; there is an increasing amount of research being done on the level of walkability and identifying pedestrian-friendly zones. In this context, the aim of the study is; this study determines the areas with high pedestrian-friendly potential on the scale of the neighborhoods that make up the city center of Ordu, which is in a rapid urbanization process. The basic method adopted for this purpose is to calculate the Pedestrian Environment Index (PEI) values, developed as a quantitative and spatial scale, and to reveal them spatially. PEI; it consists of five sub-indices: land use diversity index (LDI), intersection density index (IDI), commercial density index (CDI), population density index (PDI) and park density index (PaDI). Neighborhoods within the scope of the study; the Pedestrian Environment Index values obtained because of the analysis were compared in terms of having a pedestrianfriendly environment. As a result; Yeni, Düz, and Şarkiye neighborhoods, which offer many alternatives in terms of trade and shopping areas and have a high variety of use, are more pedestrian friendly than neighborhoods with low YCI values. The neighborhoods with the lowest pedestrian-friendliness are Kirazlimanı, Aziziye, and Güzelyalı.
\end{abstract}

${ }^{1}$ Ordu University, Faculty of Agriculture, Landscape Architecture Department, mesutguzel@odu.edu.tr

${ }^{2}$ Ordu University, Faculty of Agriculture, Landscape Architecture Department, muraty25@hotmail.com 
KEYWORDS: Pedestrian zones, Walkability, Active transportation, Pedestrian Environment Index, Ordu.

\section{ÖZ:}

Kentlerin birçoğu, insanların yaşadıkları yerler ile çalıştıkları, alışveriş yaptıkları ya da boş zamanlarını geçirdikleri alanlar arasında motorlu taşıt kullanımı gerektiren uzun mesafeler olacak şekilde kurgulanmıştır. Ancak son zamanlarda tüm dünyayı etkisi altına alan küresel salgın, ulaşım tercihlerinin ve kentsel mekân kurgularının sorgulanmasına neden olmuştur. Küresel salgınla mücadele kapsamında ulaşımın ve kamusal hareketliliğin kısıtlanması, yaya dostu kentlerin önemini bir kez daha vurgulamıştır. Yaya dostu bir kent; sakinlerinin yürüyerek ya da bisiklete binerek, çok kısa mesafelerde, alışveriş, eğitim, sağlık ve rekreasyon gibi temel ihtiyaçlarını karşılayabildiği bir yaşam ortamıdır. Dünyanın çeşitli kentlerinde; yürümeye elverişlilik düzeyi ve yaya dostu bölgelerin belirlenmesi üzerine giderek artan sayıda araştırma yapılmaktadır. Bu kapsamda çalışmanın amacı; hızlı bir kentleşme sürecinde olan Ordu'nun kent merkezini oluşturan mahalleler ölçeğinde yaya dostu olma potansiyeli yüksek bölgelerin belirlenmesidir. Bu amaç doğrultusunda benimsenen temel metot, kantitatif ve mekânsal bir ölçek olarak geliştirilen Yaya Çevre İndisi (YCI) değerlerinin hesaplanarak mekânsal olarak ortaya konmasıdır. YCI; alan kullanım çeşitliliği indisi (AKCI), kavşak yoğunluğu indisi (KYI), ticari yoğunluk indisi (TYI), nüfus yoğunluğu indisi (NYI) ve park yoğunluğu indisi (PYI) olmak üzere beş alt indisten oluşmaktadır. Çalışma kapsamındaki mahalleler; analiz sonucunda elde edilen Yaya Çevre İndisi değerleri kullanılarak yaya dostu bir çevreye sahip olma yönünden karşılaştırılmıştır. Sonuç olarak; ticaret ve alışveriş alanları yönünden çok sayıda alternatif sunan, alan kullanım çeşitliliğinin yüksek olduğu Yeni, Düz ve Şarkiye mahalleleri YCI değerleri düşük olan mahallelere göre daha yaya dostu çıkmıştır. Yaya dostu olma bakımından en yetersiz mahalleler ise Kirazlimanı, Aziziye ve Güzelyalı mahalleleridir.

ANAHTAR KELIMELER: Yaya bölgeleri, Yürünebilirlik, Aktif ulaşım, Yaya Çevre İndisi, Ordu.

\section{“Ordu Kent Merkezindeki Yaya Dostu Bölgelerin Yaya Çevre İndisi Kullanılarak Belirlenmesi”}

\section{GİRIŞ:}

Bugün, dünya nüfusunun yarıdan fazlası kentsel alanlarda yaşamaktadır. Birleşmiş Milletler tarafından yayımlanan raporda; 2018 yılı itibariyle yalnızca Avrupa ülkelerindeki insanların yaklaşık \%75'inin kentlerde ve kentlerin yakın çevresinde ikamet ettiği ifade edilmiştir. Bununla birlikte, geleceğe yönelik yapılan modellemelerde, kentlerde yaşayan nüfusun toplam nüfusa oranının 2040 yılında \%80'e, 2050 yılında ise yaklaşı \%85'e ulaşması öngörülmektedir (BM, 2019). Günümüz kentlerinde konut bölgeleri, ticaret alanları ve rekreasyon amaçlı kullanılan alanlar genellikle birbirinden uzak konumlarda yer almaktadır. Bu da insanların yaşadıkları yerler ile çalıştıkları, alışveriş yaptıkları ya da boş zamanlarını geçirdikleri alanlar arasındaki ulaşım mesafesini ve süresini uzatmaktadır (Duany ve diğerleri, 2001). Yapılan bir çalışma yürüyüşlerin çoğunun 600 m'den daha kısa olduğunu ve çok azının 1200 m'yi aştığını göstermiştir (Millward ve diğerleri, 2013). Genellikle kent insanının temel gereksinimleri bu kadar kısa mesafelerde çözülemediğinden, yürüyüş ya da bisiklete binmek gibi fiziksel güç gerektiren ulaşım şekilleri yerine motorlu taşıllar tercih edilmektedir (Koh ve Wong, 2013; Gori ve diğerleri, 2014). Bireylerin ulaşım tercihlerini yönlendiren diğer bir etken de kendileri için ayrılan bölgelerin hangi niteliklere sahip olduğudur. Bakımlı kaldırımları ve yeterli aydınlatmaya sahip yolları olan, içerisinde cezbedici ve şaşırtıcı ögeleri barındıran bölgelerde yaşayan insanların yürüyüş veya bisiklet gibi aktif ulaşım yöntemlerini kullanma olasılığı daha fazladır (Frank ve diğerleri, 2006; Saelens ve Handy, 2008; Larco ve diğerleri, 2012). Bu durumun tersi düşünüldüğünde, yürüyüş yapılan çevrenin kalitesiz ve standartlara uygun olmaması bireylerin yürüyüş yapma motivasyonlarını kırmaktadır (Yameqani ve Alesheikh, 2019).

Son yıllarda kentsel alanlarda "yaya dostu” yerleşimlerin oluşturulması üzerinde durulmaktadır (Azmi ve Karim, 2012). Buradaki yaya dostu ortam temel olarak; yayaların kullanımına sunulan cadde ve kaldırımların rahat, geniş ve konforlu olduğu, yayalara güven aşılayan ve ilginç deneyimler sunan bir ortam olarak tanımlanmaktadır (Speck, 2013). Ancak bu tanımın kapsamını genişletmek mümkündür. İnsanların motorlu taşıtlara bağımlı olmadan yaşayabildiği, çalışabildiği, alışveriş yapabildiği, dinlenebildiği ve diğer insanlarla sosyalleşebildiği, günlük ihtiyaçların yürünebilir mesafelerde karşılandığı çevreler "yaya dostu" olarak nitelendirilmektedir (Saligaros, 2010). Özellikle içerisinde bulunduğumuz küresel Covid-19 salgını döneminde, hükümetlerce alınan tedbirler gereği ulaşımın ve kamusal hareketliliğin kısıtlanması yaya dostu çevrelerin önemini bir kez daha vurgulamıştır (Musselwhite ve diğerleri, 2020). 
Küresel salgın nedeniyle büyük, orta ve kısa mesafelerde seyahatler sınırlandırılmış, sosyal ilişkilerin yoğunluğu büyük ölçüde azaltılmıştır (Zecca ve diğerleri, 2020). Ulaşımın kısıtlanması sonucunda tek merkezli kentlerden çok merkezli kentlere geçiş gündeme gelmiştir. Bu düşüncenin temelinde; sağlık tesisleri, rekreasyon alanları, okullar ve diğer kamu hizmetlerinin kentin belli noktalarında yoğunlaşmaması ve tüm kentsel dokuya dağıtılması, yerel merkezlerin güçlendirilmesi bulunmaktadır (Megahed ve Ghoneim, 2020). New York (ABD) merkezli ve kâr amacı gütmeyen bir sivil toplum kuruluşu olan Ulaştırma ve Kalkınma Politikaları Enstitüsü’nün, dünya kentlerinin yaya dostu olma ve yürünebilirlik düzeylerini değerlendirmek üzere hazırladığı rapora (Pedestrians First, 2021) göre; 100 m içerisinde araç trafiğine kapalı alanlara erişimin en yüksek olduğu ilk beş kent sırasıyla; Hong Kong (Çin), Moskova (Rusya), Paris (Fransa), Bogotá (Kolombiya) ve Londra (Birleşik Krallık) olarak belirlenmiştir. Bununla birlikte, $1 \mathrm{~km}$ mesafe içerisinde sağlık ya da eğitim kurumlarına olan erişilebilirliğin en yüksek olduğu kent Paris'tir. Nispeten küçük bina blokları, yayaların büyük binaların etrafından dolanmaksızın doğrudan hedeflerine yürümelerini kolaylaştırdığından aynı raporda yaya dostu olmanın bir başka ölçütü olarak değerlendirilmiştir. Bu kritere göre ise Sudan'ın başkenti Hartum birinci sırada gelirken, bunu sırasıyla Bogotá (Kolombiya), Peru’nun başkenti Lima, Karaçi (Pakistan) ve Tokyo (Japonya) takip etmektedir (Carrington, 2020).

Literatürde yaya dostu çevreler ile bağlantılı olarak "yürünebilirlik” ve "aktif ulaşım” gibi kavramların ön plana çıktığını görmek mümkündür (Frank ve diğerleri, 2006; Frank ve diğerleri, 2010; Azmi ve Karim, 2012; Dobesova ve Krivka, 2012; Larco ve diğerleri, 2012; Rabl ve De Nazelle, 2012; Gori ve diğerleri, 2014; Gorrini ve Bertini, 2018; Yameqani ve Alesheikh, 2019). Yürünebilirlik kavramı, Leslie ve diğerleri (2007) tarafından "yapılı çevrenin ve arazi kullanım özelliklerinin, insanların işe gitme, rekreasyon alanlarına ve temel hizmetlere erişme gibi amaçlar için yürümelerine elverişlilik düzeyi” olarak tanımlanmıştır. Aktif ulaşım kavramı ise yürünebilirlikten farklı olarak yürüyüş ve bisiklet kullanımını birlikte içerir. Her ikisi de fosil yakıt kullanımı gerektirmeyen ulaşım şekilleri olduğundan karbon emisyonuna ya da hava kirliliğine neden olmamaktadır (Komanoff ve diğerleri, 1993). Bu yönüyle çevre dostu bir yaklaşımdır.

Bugün ulaşım alışkanlıklarımızı değiştirme ihtiyacına dair giderek artan bir farkındalık oluşmaktadır (Iacono ve diğerleri, 2010; Rabl ve De Nazelle, 2012). Şüphesiz bu farkındalığın oluşmasında ve artırılmasında kentsel politikaların rolü büyüktür. Dünyanın dört bir yanındaki metropollerde şehir planlamacıları alternatif ulaşım yöntemleri üzerine çalışmaktadır ve yaya dostu bir kent tesis etme noktasında özellikle yürünebilirliğin önemli bir rol oynadığına inanmaktadırlar (Yameqani ve Alesheikh, 2019). Benzer şekilde aktif ulaşımı destekleyen politikalar; motorlu taşıtlara bağımlılı̆̆ı azaltan, yürüyüşü ve bisiklet kullanımını teşvik eden, pek çok ihtiyaca cevap veren karma bir alan kullanım yapısının hâkim olduğu çevreler oluşturma üzerine kurulmuştur (Peiravian ve diğerleri, 2014; Gehrke, 2017). Peiravian ve diğerlerine göre (2014) aktif ulaşım, yakın geleceğin kentlerinde oldukça önemli bir yere sahip olacaktır.

Aktif ulaşımla birlikte artan fiziksel aktivitenin insanların bedensel ve ruhsal sağlığı üzerinde önemli olumlu etkileri bulunmaktadır. Her şeyden önce yürüyüş ya da bisiklete binme gibi aktif ulaşım türleri ulaşımı sağlama işlevinin yanında aynı zamanda rekreasyonel bir boyuta sahiptir (Yameqani ve Alesheikh, 2019). Aktif ulaşımın bir diğer yararı da obezite ve diyabet gibi çağımızın hastalıklarıyla karşılaşma riskini düşürmesidir. Yapılan araştırmalar, daha "yürünebilir" ya da "bisikletle gezilebilir" mahallelerde yaşayan insanların, motorlu ulaşım gerektiren mahallelerde yaşayanlara göre fazla kilolu ya da obez olma olasılığının daha düşük olduğunu göstermiştir (Frank ve diğerleri, 2004; Frank ve diğerleri, 2010; Creatore ve diğerleri, 2016; Yameqani ve Alesheikh, 2019).

2013 yılında büyükşehir statüsü verilen Ordu ilinin kent merkezi doğu ve güney yönlerinde gelişim göstermektedir. Kent merkezindeki mevcut yerleşimlerin bulunduğu mahalleler ile kentin gelişim alanlarını oluşturan mahallelerin "yaya dostu” olma sürecinin neresinde olduklarının belirlenmesi, yürünebilirlik ve aktif ulaşım odaklı kentsel planlamalara 1şık tutacaktır. Bu bağlamda çalışmanın amacı; Ordu kent merkezini oluşturan mahalleler ölçeğinde yaya dostu olabilecek ve aktif ulaşımının yürünebilirlik ayağında potansiyeli yüksek olan bölgelerin belirlenmesidir. Bu noktada, yaya dostu çevrelerin belirlenmesinde kantitatif ve mekânsal bir ölçek olarak geliştirilen Yaya Çevre İndisi (YCI) kullanılmıştır. YCI esas olarak; alan kullanım çeşitliliği indisi (AKCI), kavşak yoğunluğu indisi (KYI), ticari yoğunluk indisi (TYI), nüfus yoğunluğu indisi (NYI) ve park yoğunluğu indisi (PYI) olmak üzere beş alt indisten oluşmaktadır. Çalışma kapsamındaki mahalleler; analiz sonucunda elde edilen YCI değerleri kullanılarak yaya dostu bir çevreye sahip olma yönünden karşılaştırılmıştır. 


\section{MATERYAL ve YÖNTEM:}

Çalışma alanı; Ordu kent merkezini oluşturan ve Altınordu ilçesine bağlı 21 merkez mahalle (Akyazı, Aziziye, Bahçelievler, Bucak, Cumhuriyet, Durugöl, Düz, Güzelyalı, Karapınar, Karşıyaka, Kirazlimanı, Kumbaşı, Saray, Selimiye, Subaşı, Şahincili, Şarkiye, Şirinevler, Taşbaşı, Yeni, Zaferimilli) olarak belirlenmiştir (Şekil 1, 2). 2020 yılı itibariyle 21 mahallenin toplam nüfusu 173.628 kişidir (TÜİK, 2021).
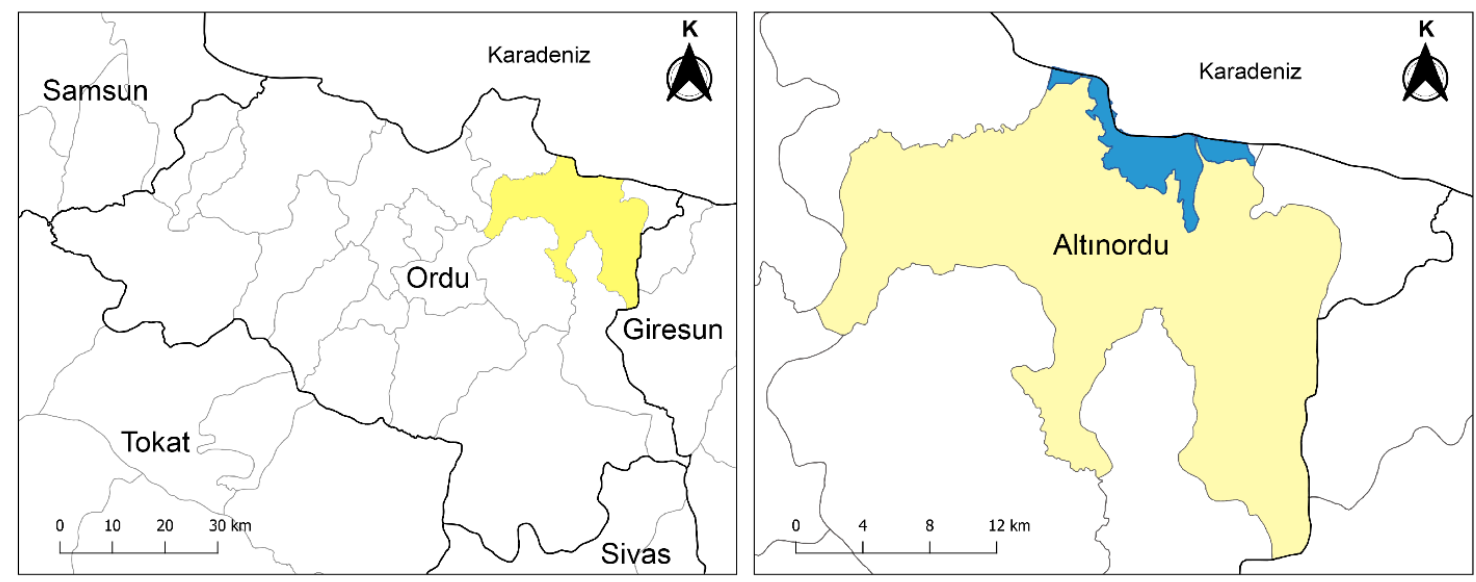

Şekil 1. Çalışma alanının konumu

Yaya çevre indisi (YCI) ve alt indislerin hesaplanabilmesi için çalışma alanının belirli büyüklükte parçalara ayrılması gerekmektedir. Peiravian ve diğerleri (2014) Chicago kentinde yaptıkları çalışmada "sub-TAZ" adı verilen alt trafik analiz bölgesi sınırlarını esas almıştır. Bununla birlikte nüfus sayım bölgesi, mahalle sınırları gibi farklı boyut ve şekildeki alan bölümlemelerinin de yönteme uygun olduğunu belirtmişlerdir. Bu bağlamda çalışmada 21 mahalleyi kapsayan çalışma alanının sınırları esas alınmış ve QGIS 3.16.5 yazılımındaki “Create grid” aracı ile 200x200 m'lik bir karelaj ağı oluşturulmuştur (QGIS.org, 2021). Bu karelaj sistemi toplam 811 kareden oluşmaktadır (Şekil 2).

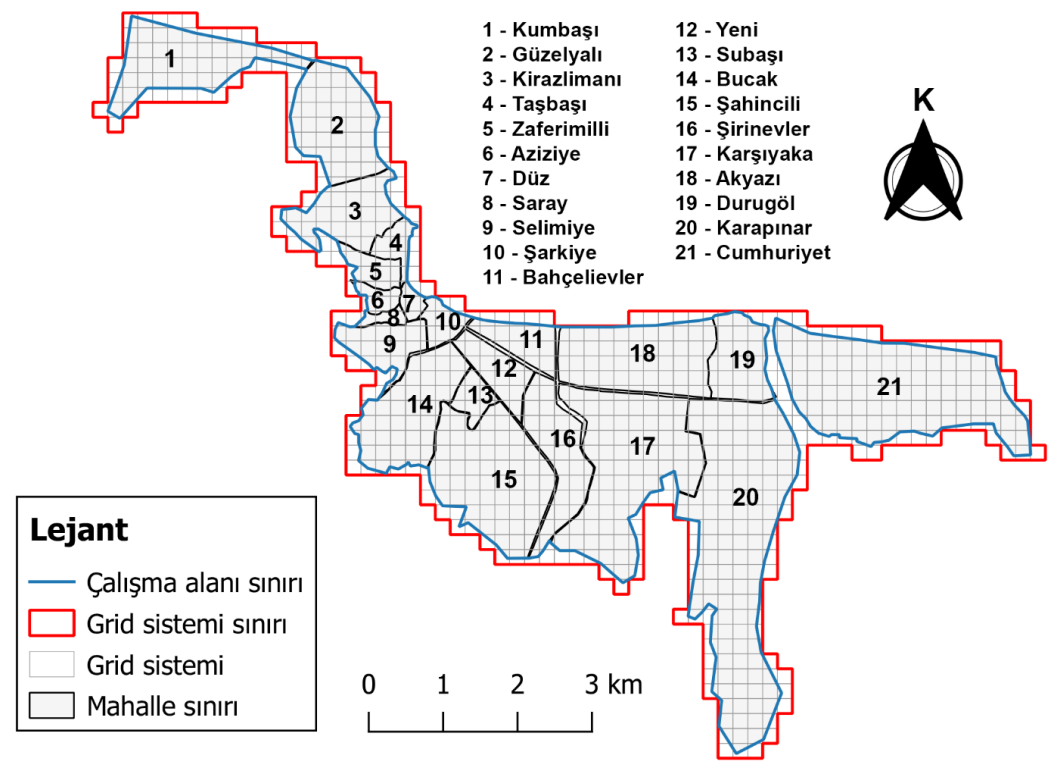

Şekil 2. Çalışma alanı sınırı ve 200x200 m'lik grid sistem 


\subsection{Yaya Çevre İndisi (YCI)}

Yaya çevre indisi (YCI), Peiravian ve diğerleri (2014) tarafindan kentsel alanlar için yaya dostu bölgelerin belirlenmesi amacıyla kolayca hesaplanabilen bir değerlendirme ölçütü olarak geliştirilmiştir. Yaya çevre indisi esasında dört alt indisin değerleri kullanılarak hesaplanmaktadır (Denklem 1). Bunlar; alan kullanım çeşitliliği indisi (AKCI), kavşak yoğunluğu indisi (KYI), ticari yoğunluk indisi (TYI) ve nüfus yoğunluğu indisi (NYI)'dir.

$$
Y C I_{i}=\frac{1}{16} x\left[\left(1+A K C I_{i}\right) x\left(1+K Y I_{i}\right) x\left(1+T Y I_{i}\right) x\left(1+N Y I_{i}\right)\right]
$$

Bununla birlikte yaya çevre indisi, geliştirilmeye ve farklı alt indisler ile desteklenmeye uygun olarak tasarlanmıştır. Çalışma kapsamında bu mevcut formüle bir başka alt indis olarak hesaplanabilen park yoğunluğu indisi (PYI) eklenmiştir. Formülün yapısı gereği, alt indis değerlerinin birer fazlaları çarpılarak 2'nin alt indis sayısı kadar kuvvetine bölünmektedir. Dolayısıyla yeni durumda beş alt indis olduğundan nihai durumda çarpımlar 2'nin beşinci kuvveti olan 32'ye bölünmüsstür (Denklem 2). Alt indislerin sayısı arttırıldıkça bu düzenlemenin yapılması gerekmektedir. Yaya çevre indisinin ve diğer tüm alt indisler, formül gereği 0 ile 1 arasında değer almaktadır.

$Y C I_{i}=\frac{1}{32} x\left[\left(1+A K C I_{i}\right) x\left(1+K Y I_{i}\right) x\left(1+T Y I_{i}\right) x\left(1+N Y I_{i}\right) x\left(1+P Y I_{i}\right)\right]$

Yaya çevre indisinin hesaplanmasında kullanılan alt indisler, bu indislerin formülleri ve formüllerdeki bileşenler aşağıda detaylı olarak açıklanmıştır.

\subsection{Alan Kullanım Çeşitliliği İndisi (AKCI)}

Arazi kullanım çeşitliliği indisi (AKCI), belirli bir bölgedeki arazi kullanımındaki heterojenliğin bir göstergesi olarak hesaplanmaktadır (Peiravian ve diğerleri, 2014). İndisin temeli, biyolojik çeşitlilik hesabında ve ekonomi alanında yaygın olarak kullanılan Shannon (1948) entropisine dayanmaktadır. AKCI değerinin yüksek olması, daha çeşitli ve karmaşık bir arazi kullanımının olduğunu göstermektedir. Arazi kullanımındaki bu çeşitlilik, bireylerin yürüme mesafesinde birçok ihtiyacını karşılayabileceği yaya dostu bir çevre anlamına gelmektedir (Loo ve Chow, 2006).

Çalışma alanı içerisindeki alan kullanım tipleri dokuz başlıkta toplanmışıtır. Bunlar; konut alanı (Şekil 3b), ticaret alanı (Şekil 3c), sanayi alanı (Şekil 3d), rekreasyon alanı, eğitim alanı, sağlık alanı, resmi kurum alanı, dini tesis alanı ve mezarlık alanlarıdır. Alan kullanım çeşitliliği indisinin hesaplanabilmesi için öncelikle her bir karenin $E_{i}$ değeri hesaplanmalıdır. Bir karede tek bir alan kullanımı bulunuyorsa $E_{i}$ değeri 0 olarak kabul edilir. Alan kullanımı sayısı birden fazla ise Denklem 3'teki Shannon entropisine dayanan formül kullanılır. Formüldeki $p_{j}$, her bir alan kullanım sınıfına ait alanın 200x200 m'lik karenin toplam alanına oranını, ki karedeki farklı alan kullanımlarının sayısını ifade etmektedir (Peiravian ve diğerleri, 2014). Grid sistemdeki her kare için hesaplanan $E_{i}$ değerleri, sistemdeki en büyük $E_{i}$ değerine oranlanarak nihai AKCI değerleri elde edilmiş olur (Denklem 4).

$$
\begin{gathered}
E_{i}=\frac{-\sum_{j=1}^{k}\left(p_{j} * \ln \left(p_{j}\right)\right)}{\ln \left(k_{i}\right)}, \quad k_{i}>1 \\
=0 \quad, \quad k_{i}=1 \\
A K C I_{i}=\frac{E_{i}}{\max \left(E_{i}\right)}, \quad 0 \leq A K C I_{i} \leq 1
\end{gathered}
$$



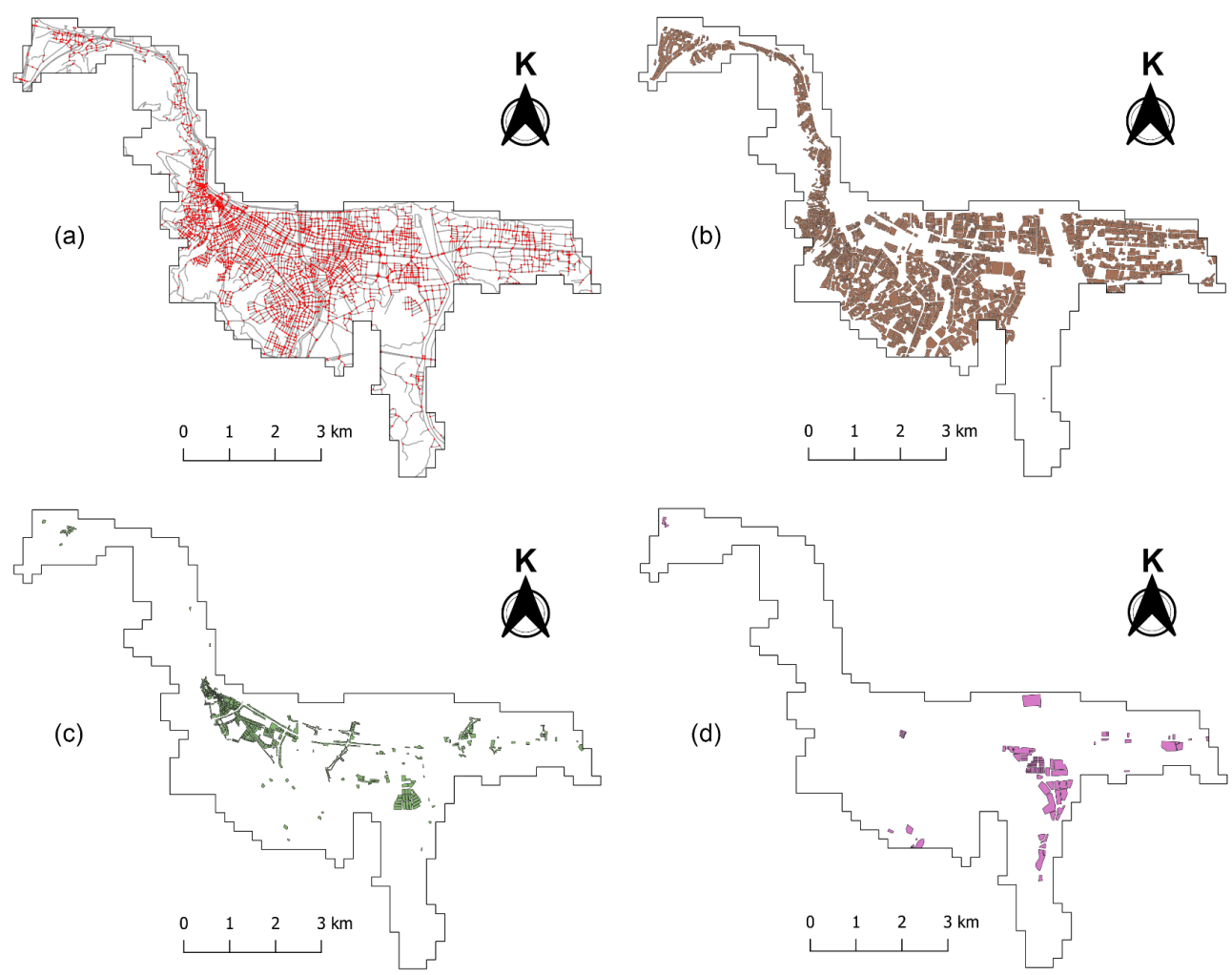

Şekil 3. Çalışma alanı içerisindeki bazı alan kullanım çeşitleri. (a) Yol ağı ve kavşak noktaları. (b) Konut alanları. (c) Ticaret alanları. (d) Sanayi alanları.

\subsection{Kavşak Yoğunluğu İndisi (KYI)}

Kavşak yoğunluğu indisi (KYI) belirli bir alandaki kavşakların ve cadde geçişlerinin yoğunluğunu ölçmektedir. KYI değerinin yüksek olması, daha küçük bina ve parsel boyutları anlamına gelmektedir. Yayalar açısından bakıldığında daha küçük parsel boyutları aslında daha fazla rota çeşitliliği ve rotayı değiştirme seçeneği sunmaktadır. Bununla birlikte bir alanda kavşak yoğunluğunun fazla olması, ulaşımda meydana gelen gecikmeden dolayı motorlu taşıt kullanımı noktasında caydırıcı olmaktadır (Peiravian ve diğerleri, 2014). Tüm bunlar göz önünde bulundurulduğunda daha yüksek KYI değerlerine sahip bölgeler diğer bölgelere oranla daha yaya dostu alanlar olmaktadır.

Kavşak yoğunluğu indisinin hesaplanmasında altlık olarak kullanılan yol ağı ve kırmızı renk ile belirtilen kavşak noktaları Şekil 3a'da görülmektedir. Denklem 5 'teki formülde yer alan $n_{i j}$, her bir kavşak noktasına bağlanan yol sayısını, $A_{i}$ her bir karenin alanını ifade etmektedir. Bir kare içerisindeki kavşak noktalarına bağlanan yol sayıları toplanarak, karenin alanına bölünerek bir değer elde edilir. Grid sistemdeki her kare için hesaplanan bu değerler, sistemdeki en büyük değere oranlanarak nihai KYI değerleri elde edilmiş olur (Denklem 5).

$K Y I_{i}=\frac{\frac{\Sigma_{j} n_{i j}}{A_{i}}}{\max \left(\frac{\Sigma_{j} n_{i j}}{A_{i}}\right)}, \quad 0 \leq K Y I_{i} \leq 1$

\subsection{Ticari Yoğunluk İndisi (TYI)}

Koh ve Wong (2013), çeşitli faktörlere ek olarak bir alandaki ticaret alanı miktarının da bireylerin yürüme davranışları üzerinde etkili olduğunu ifade etmiştir. Alışveriş ve eğlence gibi sektörleri içine alan ticari yoğunluğun yüksek olması, kısa mesafelerde insanların pek çok temel ihtiyacının karşılanabileceği anlamına gelmektedir. Dolayısıyla ticari 
yoğunluğun fazla olduğu bu tip alanlarda bireyler, uzak mesafelere taşıt ile gitmek yerine yürümeyi tercih edebilirler (Peiravian ve diğerleri, 2014). Özellikle kentsel alanlarda yürünebilirlik düzeyinin artırılması için, 150 metrelik yürüme mesafesinde, çok çeşitli alan kullanımları ve yol ağlarıyla birlikte bireylerin ihtiyaçlarına cevap verebilecek bir ticari yoğunluk ile planlanma gereksinimi bulunmaktadır (Gorrini ve Bertini, 2018). Bu bağlamda ticari yoğunluk indisi (TYI), bireylerin günlük aktiviteleri sırasında ihtiyaç duyabilecekleri farklı ticari, finansal ve diğer hizmetlerin varlığını temsil etmektedir (Peiravian ve diğerleri, 2014).

Denklem 6'daki formülde yer alan $G F A_{i}$, brüt kat alanını, $A_{i}$ her bir karenin alanını ifade etmektedir. Brüt kat alanı (GFAi), ticari amaçla kullanılan bina alanının kat sayısı ile çarpılması sonucu elde edilmektedir. Grid sistemdeki her kare için hesaplanan $G F A_{i} / A_{i}$ değerleri, sistemdeki en büyük değere oranlanarak nihai TYI değerleri elde edilir (Denklem 6).

$T Y I_{i}=\frac{\frac{G F A_{i}}{A_{i}}}{\max \left(\frac{G F A_{i}}{A_{i}}\right)}, \quad 0 \leq T Y I_{i} \leq 1$

\subsection{Nüfus Yoğunluğu İndisi (NYI)}

Nüfus yoğunluğu indisi (NYI), belirli bir bölgedeki nüfus yoğunluğunu temsil eder. Daha yüksek NYI değerleri, incelenen alanda daha fazla insanın ikamet etmesi anlamına gelir. İnsan yoğunluğunun fazla olmasının, yürümek için daha güvenli ve emniyetli bir ortam sağladığı kabul edilmektedir (Peiravian ve diğerleri, 2014). Yürüme mesafesinin daha kısa olması beklenen kent merkezleri genellikle daha yüksek NYI ortalamasına sahiptir (Dobesova ve Krivka, 2012).

Denklem 7'de yer alan formülde $P_{o p}$, incelenen karedeki toplam nüfusu, $A_{i}$ ise karenin alanını ifade etmektedir. Diğer indislerdeki benzer şekilde burada da grid sistemdeki her kare için hesaplanan $P o p_{i} / A_{i}$ değerleri, sistemdeki en büyük değere oranlanarak nihai NYI değerleri elde edilir (Denklem 7). Pop $i$ değerinin hesaplanmasında ise Denklem 8'deki formülden yararlanılmıştır. Burada $P o p_{N}$ karenin bulunduğu mahallenin toplam nüfusunu, $R A_{i}$ karedeki toplam konut alanını ve $T R A_{N}$ mahalledeki toplam konut alanını ifade etmektedir (Denklem 8).

$$
\begin{aligned}
N Y I_{i} & =\frac{\frac{\operatorname{Pop}_{i}}{A_{i}}}{\max \left(\frac{\text { Pop }_{i}}{A_{i}}\right)}, \quad 0 \leq N Y I_{i} \leq 1 \\
\operatorname{Pop}_{i} & =\frac{R A_{i}}{T R A_{N}} x \operatorname{Pop}_{N}
\end{aligned}
$$

\subsection{Park Yoğunluğu İndisi (PYI)}

Park yoğunluğu indisi (PYI), Peiravian ve diğerleri (2014) tarafından geliştirilen yaya çevre indisinin dört alt indisine ek olarak hesaplanmıştır. Bu indis, belirli bir bölgedeki park yoğunluğunun kantitatif olarak ifade edilmesine olanak tanımaktadır. Park yoğunluğunun fazla olması, bireylerin rekreasyon ihtiyacını karşılamaları için uygun bir ortam yaratacağından park yoğunluğunun düşük olduğu bölgelere göre daha fazla yaya dostu olduğu anlamına gelmektedir.

Park yoğunluğu indisi (PYI), Denklem 9'daki formül ile hesaplanmaktadır. Burada; $P A_{i}$ bir karedeki toplam park alanını, $A_{i}$ ise karenin toplam alanını ifade eder. Grid sistemdeki her kare için hesaplanan PAi / $A_{i}$ değerleri, sistemdeki en büyük değere oranlanarak nihai PYI değerleri elde edilmiş olur (Denklem 9).

$P Y I_{i}=\frac{\frac{P A_{i}}{A_{i}}}{\max \left(\frac{P A_{i}}{A_{i}}\right)}, \quad 0 \leq P Y I_{i} \leq 1$

\subsection{Mekânsal ve İstatistiksel Analiz}


Çalışmanın temelini oluşturan yaya çevre indisi (YCI) ve diğer alt indislerin hesaplanması, haritalanması ve görselleştirilmesinde açık kaynak kodlu ve ücretsiz bir yazılım olan QGIS 3.16.5 yazılımından yararlanılmışır (QGIS.org, 2021).

Yaya çevre indisi (YCI) ortalamalarının mahallelere göre farklılaşma durumu, R programlama dili (R Core Team, 2020) için kullanıcı dostu bir arayüz sağlayan RStudio programının 1.4.1106.0 sürümünde yapılan tek yönlü varyans analizi (One-way ANOVA) ile test edilmiştir. Farklı gruplar Post-hoc testlerinden biri olan Fisher's LSD ile belirlenmiştir. RStudio yazılımında verilerin okutulması, analiz edilmesi ve görselleştirilmesinde "readr", "agricolae", "car", "FSA" ve "dplyr" paketlerinden yararlanılmıştır (Mendiburu, 2017; Wickham ve diğerleri, 2018; Fox ve Weisberg, 2019; Ogle ve diğerleri, 2021).

İndisler arasındaki ilişkinin anlaşılması amacıyla Python programlama dili kullanılarak korelasyon analizi yapılmıştır. Yapılan analiz ve görselleştirmeler, Anaconda Navigator arayüzünden ulaşılan Jupyter Notebook 6.1.4 ortamında gerçekleştirilmiştir. Verilerin yazılım ortamına alınmasında McKinney (2010) tarafından geliştirilen "pandas" kütüphanesi, işlenmesinde ve görselleştirilmesinde ise "matplotlib" ve "numpy" kütüphaneleri kullanılmıştır (Hunter, 2007; Harris ve diğerleri, 2020).

\section{BULGULAR VE TARTIŞMA:}

Yaya çevre indisini oluşturan beş alt bileşenin çalışma alanı içerisindeki mekânsal dağılımı Şekil 4 'te verilmiştir. Saray Mahallesi yüzölçümü bakımından en küçük mahalle olmasına karşın alan kullanım çeşitliliği indisi ortalaması en yüksek mahalledir (Tablo 1). Başta Ordu Valiliği ve Altınordu Kaymakamlığı olmak üzere pek çok resmi kurum alanı bu mahallede yer almaktadır. Buna ek olarak konut, eğitim, rekreasyon alanı ve dini tesis alanı gibi çeşitli alan kullanımlarının bulunması AKCI ortalamasını yükseltmektedir (Şekil 4a). Yeni Mahalle de AKCI ortalamasının yüksek olduğu bir diğer mahalledir. Burada mezarlık ve sağlık alanı dışındaki tüm alan kullanımlarını görmek mümkündür. AKCI ortalamasının en düşük olduğu Aziziye Mahallesi büyük oranda konut alanları ile az miktarda ticaret ve rekreasyon alanından oluşmaktadır. Bu nedenle alan kullanım çeşitliliğinin düşük çıkması beklenen bir durumdur. Henüz kırsal bir yapıda olan Karapınar Mahallesi’nin güneyi ile Kirazlimanı ve Güzelyalı mahallelerinin batısına karşılık gelen yamaçlar da alan kullanım çeşitliliğinin düşük olduğu alanlardır (Şekil 4a).

Nüfusun büyük oranda kent merkezi ve çevresindeki mahallelerde yoğunlaştığı görülmektedir (Şekil 4b). Kentin önemli gelişim alanı olan Cumhuriyet Mahallesi, Karapınar Mahallesi’nin güney kesimi, Kumbaşı, Kirazlimanı ve Güzelyalı mahallelerinde nüfus yoğunluğu düşüktür.

Şekil 4c'deki kavşak yoğunluğu indisi (KYI) haritasına bakıldığında kent merkezinde daha yoğun bir kavşak varlığı görülmektedir. Bu durum yol ağının kent merkezinde daha karmaşık bir desen oluşturması ile ilişkilidir. Kavşak yoğunluğunun kent merkezinden uzaklaştıkça azalma eğiliminde olması beklenen ve literatürle uyumlu bir olgudur (Peiravian ve diğerleri, 2014).

Şekil 4d ticari yoğunluk indisinin mekânsal dağılımını göstermektedir. Kent merkezinde ve Karapınar Mahallesi’nin bir bölümünde daha yüksek TYI değerleri görülmektedir. Kent merkezindeki mevcut yaya bölgelerinde çok katlı ticaret birimlerinin bulunması sonucunda bu alanda ticari yoğunluk değerleri artmaktadır. Benzer şekilde Karapınar Mahallesi'nde sebze meyve hali ve gıda toptancılarının bulunduğu bölgede de çevreye göre daha yüksek TYI değerleri göze çarpmaktadır (Şekil 4d). TYI ortalamalarının en yüksek olduğu mahalleler ise Yeni ve Şarkiye mahalleleridir (Tablo 1).

Şekil 4e'deki haritada park yoğunluğu indisi (PYI) değerlerinin özellikle Bahçelievler ve Şarkiye mahalleleri ile Akyazı mahallesinin bir bölümünde yoğunlaştığı görülmektedir. PYI ortalamaları bakımından da Bahçelievler ve Şarkiye mahalleleri ilk sırada gelmektedir (Tablo 1). Kentin önemli sahil parkları olan Tayfun Gürsoy ve Atatürk parklarının bu mahallelerde yer alması sonucunda PYI değerleri yükselmektedir. 

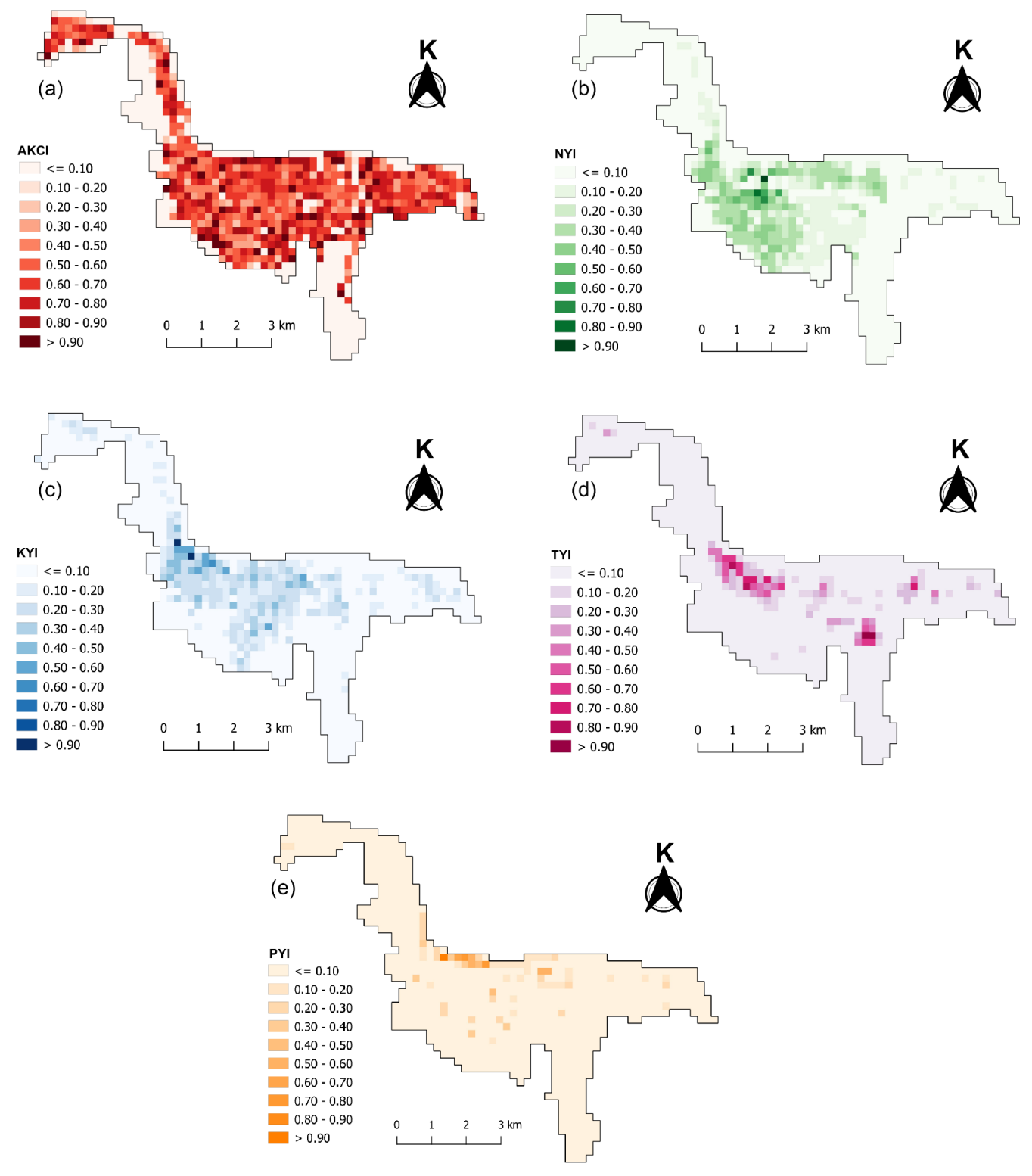

Şekil 4. Yaya çevre indisini (YCI) oluşturan bileşenlerin mekânsal dağılımı. (a) Alan kullanım çeşitliliği indisi (AKCI). (b) Nüfus yoğunluğu indisi (NYI). (c) Kavşak yoğunluğu indisi (KYI). (d) Ticari yoğunluk indisi (TYI). (e) Park yoğunluğu indisi (PYI).

Ordu kent merkezi için hesaplanan yaya çevre indisi (YCI) değerlerinin mekânsal dağılımı Şekil 5 'te verilmiştir. Yaya çevre indisi değerlerinin "Fidangör" olarak bilinen Sırrı Paşa Caddesi ile Süleyman Felek ve İsmet Paşa caddelerinin önemli bir bölümünde yüksek olduğu görülmektedir. Bu caddeler ve etraflarında gelişen bölge; alışveriş alanlarının yoğun olarak bulunması ve pek çok kamu kurumunun burada yer alması ile Ordu kentinin "kalbi" ve merkezi olarak tanımlanabilir. Özellikle son yıllarda bu alanlarda yapılan yayalaştırma ve iyileştirme faaliyetleri ile kent halkının son derece talep gösterdiği alanlar olmuştur. Bölgede gerçekleştirilen altyapı ve cephe iyileştirmeleri, kentsel donatı elemanlarının ve bitkisel materyallerin zenginleştirilmesi ile yayalar için son derece elverişli alanlara dönüşmüştür. Sonuç olarak tüm bu özellikler bir araya geldiğinde bu alanların yaya çevre indisi değerlerinin yüksek çıkması beklenen bir durumdur. 
Tablo 1. İndis ortalamalarının mahallelere göre dağılımı

\begin{tabular}{|l|l|l|l|l|l|}
\hline Mahalle & $\mathbf{A K C I}_{\text {ort }}$ & $\mathbf{N Y I}_{\text {ort }}$ & $\mathbf{T Y I}_{\text {ort }}$ & $\mathbf{K Y I}_{\text {ort }}$ & $\mathbf{P Y I}_{\text {ort }}$ \\
\hline Akyaz1 & 0.557 & 0.226 & 0.034 & 0.177 & 0.096 \\
\hline Aziziye & 0.055 & 0.134 & 0.000 & 0.080 & 0.000 \\
\hline Bahçelievler & 0.522 & 0.170 & 0.132 & 0.207 & 0.209 \\
\hline Bucak & 0.458 & 0.204 & 0.048 & 0.127 & 0.006 \\
\hline Cumhuriyet & 0.539 & 0.056 & 0.042 & 0.059 & 0.008 \\
\hline Durugö1 & 0.471 & 0.163 & 0.010 & 0.085 & 0.026 \\
\hline Düz & 0.497 & 0.151 & 0.223 & 0.436 & 0.096 \\
\hline Güzelyalı & 0.268 & 0.029 & 0.001 & 0.025 & 0.002 \\
\hline Karapınar & 0.236 & 0.015 & 0.051 & 0.039 & 0.003 \\
\hline Karşıaka & 0.558 & 0.116 & 0.049 & 0.106 & 0.004 \\
\hline Kirazliman1 & 0.151 & 0.020 & 0.000 & 0.013 & 0.001 \\
\hline Kumbaş1 & 0.369 & 0.017 & 0.014 & 0.048 & 0.006 \\
\hline Şahincili & 0.556 & 0.296 & 0.004 & 0.079 & 0.024 \\
\hline Saray & 0.620 & 0.373 & 0.000 & 0.159 & 0.000 \\
\hline Şarkiye & 0.486 & 0.000 & 0.363 & 0.376 & 0.186 \\
\hline Selimiye & 0.401 & 0.254 & 0.013 & 0.205 & 0.021 \\
\hline Şirinevler & 0.548 & 0.233 & 0.024 & 0.190 & 0.046 \\
\hline Subaş1 & 0.469 & 0.473 & 0.039 & 0.232 & 0.006 \\
\hline Taşbaş1 & 0.326 & 0.065 & 0.005 & 0.081 & 0.086 \\
\hline Yeni & 0.601 & 0.415 & 0.420 & 0.242 & 0.003 \\
\hline Zaferimilli & 0.206 & 0.066 & 0.000 & 0.127 & 0.000 \\
\hline
\end{tabular}

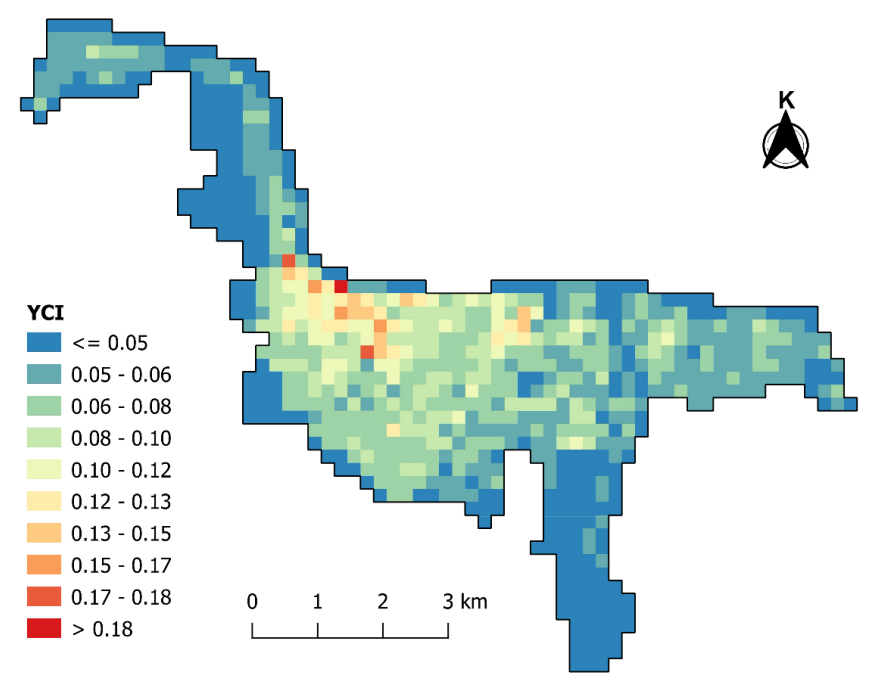

Şekil 5. Yaya Çevre İndisi’nin (YCI) mekânsal dağılımı

Yaya çevre indisini oluşturan beş alt indis göz önüne alındığında; alan kullanım çeşitliliğinin ve nüfus yoğunluğunun düşük olduğu, alışveriş merkezi, market ve pazar gibi ticaret alanları ile park alanlarının nispeten yetersiz olduğu alanlarda indis değerinin oldukça düşük olduğu görülmektedir.

Yaya çevre indisi (YCI) ortalamalarının mahallelere göre farklılaşma durumunun belirlenmesi amacıyla tek yönlü varyans analizi gerçekleştirilmiştir. Analize göre istatistiksel olarak anlamlı farklı gruplar Post-hoc testlerinden biri olan Fisher's LSD ile belirlenmiştir. Sonuçlar kutu-bıyık grafiği olarak Şekil 6'da sunulmuştur. Grafikte yer alan küçük harfler $\mathrm{p}=0.05$ düzeyinde farklı grupları ifade etmektedir. Buna göre; yaya çevre indisi ortalamasının en yüksek olduğu mahalleler, Yeni Mahalle $\left(\mathrm{YCI}_{\text {ort }}=0.1219\right)$, Düz Mahalle $\left(\mathrm{YCI}_{\text {ort }}=0.1099\right)$ ve Şarkiye Mahallesi $\left(\mathrm{YCI}_{\text {ort }}=0.1078\right)$ olup aralarında istatistiksel olarak fark bulunmamaktadır. Bu mahallelerin, YCI değerleri düşük olan mahallelere göre ticaret ve alışveriş alanları yönünden daha çok alternatife sahip, zengin alan kullanım çeşitliliği bulunan, yaya dostu mahalleler 
olduğu anlaşılmaktadır. YCI ortalamasının en düşük olduğu mahalleler ise sırasıyla; Kirazlimanı $\left(\mathrm{YCI}_{\text {ort }}=0.0378\right)$, Aziziye $\left(\mathrm{YCI}_{\text {ort }}=0.0406\right)$ ve Güzelyalı $\left(\mathrm{YCI}_{\text {ort }}=0.0427\right)$ mahalleleridir.

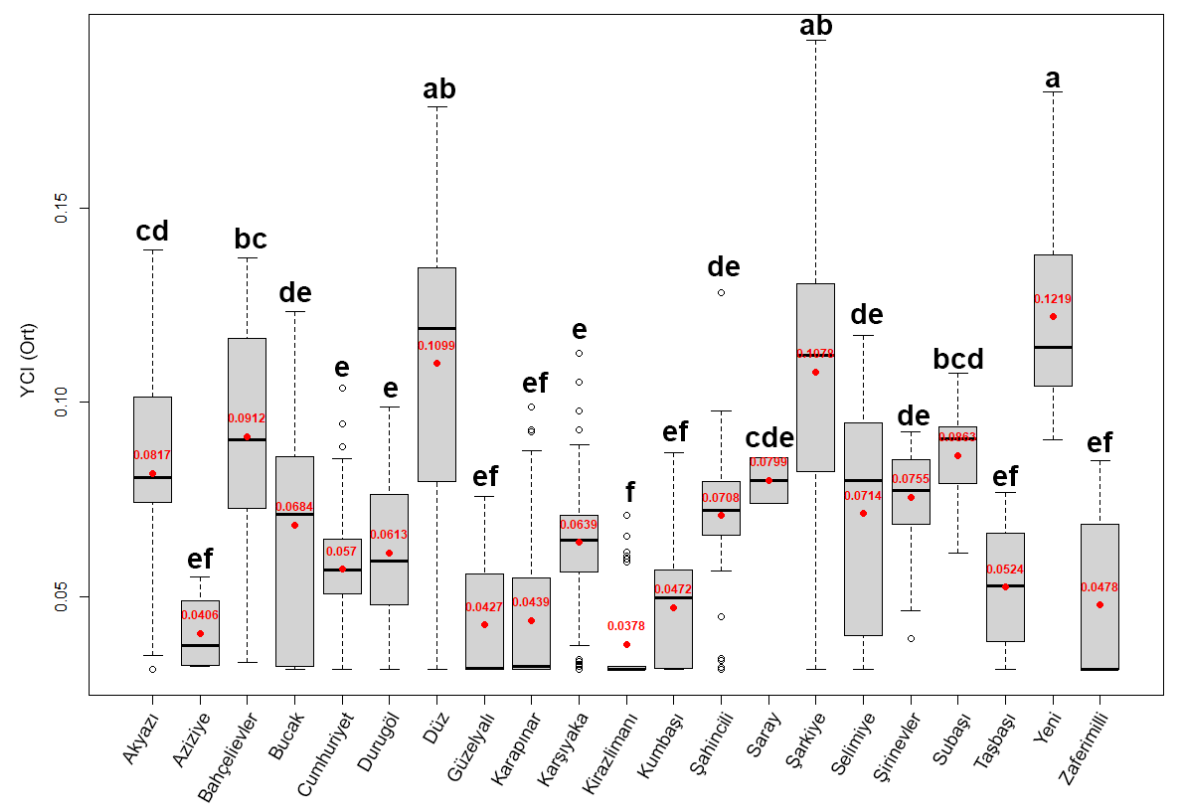

Şekil 6. Mahallelere göre Yaya Çevre İndisi (YCI) değerlerine ait kutu-bıyık grafiği (Farklı harfler, Fisher's LSD testine göre $p=0.05$ düzeyinde farklı grupları göstermektedir.)

Çalışma alanının tamamı için hesaplanan Yaya Çevre İndisi (YCI) ile bu indisin alt bileşenleri arasındaki ilişki Şekil 7'deki korelasyon matrisinde görülmektedir. YCI ve diğer tüm alt indisler arasında $p<0.001$ düzeyinde korelasyon bulunmaktadır. Yaya çevre indisi diğer beş alt indis kullanılarak hesaplanan bir değer olduğundan, YCI ile her bir alt indis arasında doğrusal ve pozitif bir ilişki olması beklenen bir durumdur (Peiravian ve diğerleri, 2014).

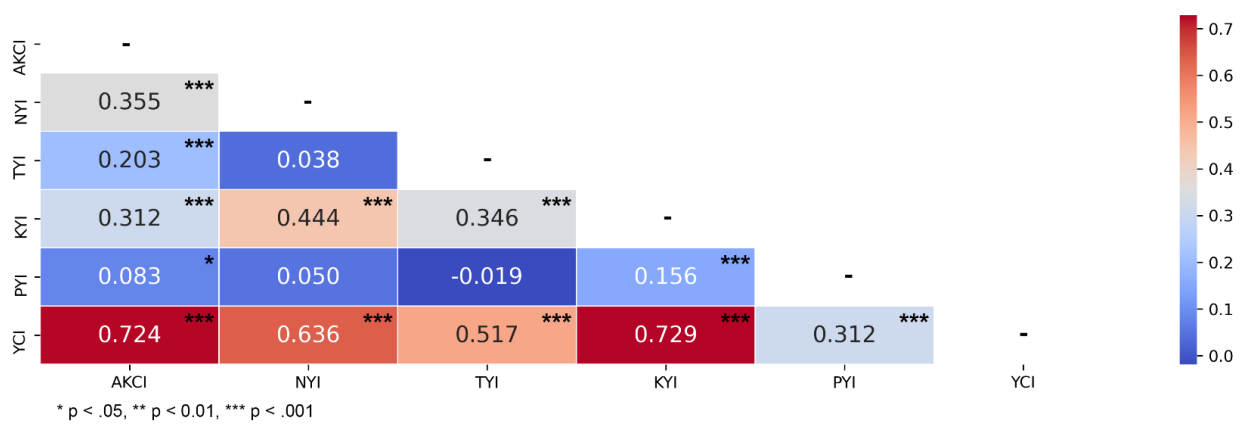

Şekil 7. Yaya Çevre İndisi’nin (YCI) ve bileşenleri arasındaki korelasyon

\section{SONUÇ:}

Kentlerin ne düzeyde "yaya dostu" oldukları genellikle yayaların kullanımına ayrılan alanların sunduğu konfor, standartlara uygunluk ve güvenlilik gibi temel nitelikler üzerinden değerlendirilmiştir. Bununla birlikte yaya dostu çevre anlayışı yalnızca yaya bölgelerinin belirli nitelik ve standartları taşıması ya da yeşil alanların erişilebilirliği ile ilgili değildir. Yaya dostu bir kent oluşturmak; kent sakinlerinin çok kısa mesafelerde, yürüyerek ya da bisiklete binerek alışveriş, eğitim, sağlık ve rekreasyon gibi temel ihtiyaçlarını karşılayabilmesi anlamına gelmektedir. Yaya dostu çevrelerin belirlenmesinde kullanılan Yaya Çevre İndisi ve alt bileşenleri, araştırmacılar tarafindan bu anlayışın odağında önerilmiştir. Ancak hesaplanan yaya çevre indisinde gelir düzeyi ve suç oranları gibi sosyo-ekonomik 
özellikler arasındaki mekânsal ilişkiler, aydınlatma ve gece kullanımlarına uygunluk, yaya bölgelerindeki kentsel donatıların ergonomik özellikleri, bitki materyalinin yaya çevresine uygunluğu, yayaların termal konfor düzeyleri gibi pek çok etken yöntem gereği göz ardı edilmiştir. Bu gibi çok çeşitli ve geniş kapsamlı kriterlerin değerlendirilmesi, elde edilen altlık haritaların coğrafi bilgi sistemleri ile mekânsal olarak analiz edilmesi çözünürlüğü yüksek sonuçların alınması yönünden önemlidir. Elde edilen çıktılar, planlayıcılara ve kent idarecilerine, kentlerin "yaya dostu" olma sürecinin neresinde olduğunu görme firsatı tanıyacaktır. Bu bağlamda, metropol anlamında bir "büyükşehir" olma sürecinin çok başında olan Ordu kentindeki yaya dostu bölge potansiyelinin ortaya konulması mevcut durumu görme açısından önemlidir. Yürünebilirlik düzeyi yüksek, yaya dostu ve aktif ulaşımı teşvik eden bir Ordu kentinde; halkın motorlu taşıtlara bağımlılığı azalacak, ulaşım kaynaklı karbon emisyonu düşecek, başta obezite ve diyabet olmak üzere çeşitli hastalıkların oranı düşecek ve bütünüyle çevre dostu bir kent ortaya çıkacaktır.

\section{Etik Standart ile Uyumluluk}

Çıkar Çatışması: Yazarlar herhangi bir çıkar çatışmasının olmadığını beyan eder.

Etik Kurul İzni: Bu çalışma için etik kurul iznine gerek yoktur.

Finansal Destek: Bu çalışma için herhangi bir finansal destek alınmamıştır.

Teşekkür: Çalışmada kullanılan istatistiksel yöntemlerin belirlenmesinde ve analizlerin gerçekleştirildiği programlama dillerinin kullanımında TÜBİTAK 2237-A Bilimsel Eğitim Etkinliklerini Destekleme Programı kapsamında desteklenen "Doğa Bilimlerinde İstatistiksel Modelleme Teknikleri (Etkinlik No: 1129B372000706)" adlı eğitimde edinilen bilgilerden yararlanılmıştır.

\section{KAYNAKÇA:}

\section{Makaleler}

Creatore, M. I., Glazier, R. H., Moineddin, R., Fazlı, G. S., Johns, A., Gozdyra, P., Booth, G. L. (2016). Association of Neighborhood Walkability with Change in Overweight, Obesity, and Diabetes. Jama, 315 (20), 2211-2220.

Frank, L. D., Andresen, M. A., Schmid, T. L. (2004). Obesity Relationships with Community Design, Physical Activity, And Time Spent in Cars. American Journal of Preventive Medicine, 27, 87-96.

Frank, L. D., Sallis, J. F., Conway, T. L., Chapman, J. E., Saelens, B. E., Bachman, W. (2006). Many Pathways from Land Use to Health: Associations Between Neighborhood Walkability and Active Transportation, Body Mass Index, and Air Quality. Journal of the American Planning Association, 72 (1), 75-87.

Frank, L. D., Sallis, J. F., Saelens, B. E., Leary, L., Cain, K., Conway, T. L., Hess, P. M. (2010). The Development of A Walkability Index: Application to the Neighborhood Quality of Life Study. British Journal of Sports Medicine, 44 (13), 924-933.

Gori, S., Nigro, M., Petrelli, M. (2014). Walkability Indicators for Pedestrian-Friendly Design. Transportation Research Record, 2464 (1), 38-45.

Gorrini, A. ve Bertini, V. (2018). Walkability Assessment and Tourism Cities: The Case of Venice. International Journal of Tourism Cities, 4 (3), 355-368.

Harris, C. R., Millman, K. J., Van Der Walt, S. J., Gommers, R., Virtanen, P., Cournapeau, D., Oliphant, T. E. (2020). Array Programming with Numpy. Nature, 585 (7825), 357-362.

Hunter, J. D. (2007). Matplotlib: A 2d Graphics Environment. IEEE Annals of the History of Computing, 9 (3), 90-95. 
Iacono, M., Krizek, K. J., El-Geneidy, A. (2010). Measuring Non-Motorized Accessibility: Issues, Alternatives, and Execution. Journal of Transport Geography, 18, 133-140.

Koh, P. P. ve Wong, Y. D. (2013). Comparing Pedestrians' Needs and Behaviours in Different Land Use Environments. Journal of Transport Geography, 26, 43-50.

Komanoff, C., Roelofs, C., Orcutt, J., Ketcham, B. (1993). Environmental Benefits of Bicycling and Walking in the United States. Transportation Research Record, 1405, 7-7.

Larco, N., Steiner, B., Stockard, J., West, A. (2012). Pedestrian-friendly Environments and Active Travel for Residents of Multifamily Housing: The Role of Preferences and Perceptions. Environment and Behavior, 44 (3), $303-333$.

Leslie, E., Coffee, N., Frank, L., Owen, N., Bauman, A., Hugo, G. (2007). Walkability of Local Communities: Using Geographic Information Systems to Objectively Assess Relevant Environmental Attributes. Health Place, 13, 111 -122.

Loo, B. P. ve Chow, S. Y. (2006). Sustainable Urban Transportation: Concepts, Policies, and Methodologies. Journal of Urban Planning and Development, 132 (2), 76-79.

Megahed, N. A. ve Ghoneim, E. M. (2020). Antivirus-Built Environment: Lessons Learned from Covid-19 Pandemic. Sustainable Cities and Society, 61, 102350.

Millward, H., Spinney, J., Scott, D. (2013). Active-Transport Walking Behavior: Destinations, Durations, Distances. Journal of Transport Geography, 28, 101-110.

Musselwhite, C., Avineri, E., Susilo, Y. (2020). The Coronavirus Disease Covid-19 and Implications for Transport and Health. Journal of Transportation Health, 16, 100853.

Peiravian, F., Derrible, S., Ijaz, F. (2014). Development and Application of the Pedestrian Environment Index (PEI). Journal of Transport Geography, 39, 73-84.

Rabl, A. ve De Nazelle, A. (2012). Benefits of Shift from Car to Active Transport. Transport Policy, 19 (1), $121-131$.

Saelens, B. E. ve Handy, S. L. (2008). Built Environment Correlates of Walking: A Review. Medicine and Science in Sports and Exercise, 40, 550-566.

Shannon, C. (1948). A Mathematical Theory of Communication. Technical Journal, 27, 379-423.

Yameqani, A. S. ve Alesheikh, A. A. (2019). Predicting Subjective Measures of Walkability Index from Objective Measures Using Artificial Neural Networks. Sustainable Cities and Society, 48, 101560.

Zecca, C., Gaglione, F., Laing, R., Gargiulo, C. (2020). Pedestrian Routes and Accessibility to Urban Services: An Urban Rhytmic Analysis on People's Behaviour Before and During the Covid-19. Journal of Land Use, Mobility and Environment, 13 (2), 241-256.

\section{Bildiriler}

Azmi, D. I. ve Karim, H. A. (2012). Implications of Walkability Towards Promoting Sustainable Urban Neighbourhood. Procedia- Social and Behavioral Sciences 50, 204-213.

Mckinney, W. (2010). Data Structures for Statistical Computing in Python. In Proceedings of the 9th Python in Science Conference, 445, 51-56.

\section{Tezler}


Gehrke, S. R. (2017). Land Use Mix and Pedestrian Travel Behavior: Advancements in Conceptualization and Measurement (Doktora Tezi, Portland State University). Erişim Adresi: https://pdxscholar.library.pdx.edu/open_access_etds/3477

\section{Kitaplar ve Kitap Bölümleri}

Dobesova, Z. ve Krivka, T. (2012). Walkability Index in the Urban Planning: A Case Study in Olomouc City. In: Burian, J. (Ed.), Advances in Spatial Planning. Intech Publications, Rijeka, Croatia, pp. 179-196.

Duany, A., Plater-Zyberk, E., Speck, J. (2001). Suburban Nation: The Rise of Sprawl and the Decline of the American Dream, North Point Press: New York.

Fox, J. ve Weisberg, S. (2019). An R Companion to Applied Regression. Sage, Thousand Oaks: CA.

Speck, J. (2013). Walkable City: How Downtown Can Save America, One Step at A Time; North Point Press: New York, USA.

\section{Raporlar}

Birleşmiş Milletler-B.M. (2019). World Urbanization Prospects 2018 Highlights, Department of Economic and Social Affairs, Trends in Urbanization. Erişim Adresi: https://population.un.org/wup/publications/files/wup2018highlights.pdf

\section{Web Sayfaları}

Carrington, D. (2020). Study Reveals World's Most Walkable Cities. Erişim Adresi: https://www.theguardian.com/cities/2020/oct/15/study-reveals-worlds-most-walkable-cities.

Mendiburu, F. $\quad$ D. (2017). Package 'Agricolae'. Erişim Adresi: https://cran.rproject.org/web/packages/agricolae/agricolae.pdf.

Ogle, D. H., Wheeler, P., Dinno, A. (2021). FSA: Fisheries Stock Analysis. R Package Version 0.8. Erişim Adresi: https://cran.r-project.org/web/packages/fsa/fsa.pdf.

Pedestrian First (2021). Pedestrian First-Tools for A Walkable City. Erişim Adresi: https://pedestriansfirst.itdp.org.

Qgis.org (2021). QGIS Geographic Information System. Erişim Adresi: http://www.qgis.org.

R Core Team (2020). R: A Language and Environment for Statistical Computing. R Foundation for Statistical Computing, Vienna, Austria. Erişim Adresi: https://www.r-project.org.

Saligaros, N. (2010). P2p Urbanism. Creative Commons Online Report. Erişim Adresi: http:// zeta.math.utsa.edu/ $\sim$ yxk833/p2purbanism.pdf.

TÜİK (2021). Türkiye İstatistik Kurumu. Erişim Adresi: https://www.tuik.gov.tr.

Wickham, H., François, R., Henry, L., Müller, K. (2018). Dplyr: A Grammar of Data Manipulation. R Package Version 0.7.6. Erişim Adresi: https://cran.r-project.org/package=dplyr. 